\title{
Investigation on the Mathematical Professional Quality of Free Normal College Students
}

\author{
Yanfeng Chen ${ }^{1, a^{*}}$ \\ ${ }^{1}$ College of Mathematics, Tonghua Normal University, China \\ ayfchenth@126.com
}

\begin{abstract}
Keywords: Mathematical knowledge; Mathematical ability; Mathematical affection; Mathematical professional quality; Free normal college students
\end{abstract}

\begin{abstract}
Mathematical knowledge, mathematical ability and mathematical affection are the main factors that affect the professional quality of free normal college students. Tuition free normal students' mathematical affection quality with higher degree, the level of mathematical ability quality is low; mathematical professional quality has difference between gender and grade; mathematical professional quality and mathematical knowledge, mathematical ability and mathematical affection are positively related; there is different influence on mathematical professional quality of free normal students, even for mathematical knowledge, mathematical ability and mathematical affection.
\end{abstract}

\section{Introduction}

The implementation of "High School Mathematics Curriculum Standard (Experiment )" require primary and secondary school mathematics teachers and students have newer, higher level [1]. The professional quality of normal college students is a hot issue in the current research of teacher education, and it is also a serious problem in the mathematics education in normal colleges [2-5]. However, it is an indisputable fact that the professional quality of normal university students should be improved urgently.

At present, scholars at home and abroad have a lot of research results about mathematical quality (different scholars use different words and expressions). Guang Dehuai and $\mathrm{Xu}$ Binyan take mathematical literacy as a comprehensive reflection of mathematics emotion attitude and values, mathematical knowledge, mathematical ability, the lack of any one dimension, are difficult to form a complex literacy [6]. Cheng Guangwen believes that the connotation of mathematical quality includes the following aspects: mathematical knowledge concept, mathematical ability, creative ability and mathematical thinking quality [7]. Qian Peiling thinks, high teacher mathematics education major students should have 3 aspects of mathematical quality [8]. Ding Fengzhao, Wang Yueting believes that a math teacher's important quality and ability to show 6 aspects [9-10]. In foreign countries, the research of mathematical teachers' professional quality is more and more, and gradually form a comprehensive mathematical quality view. For example, in the United States, a variety of teacher certification and standards are the basis for reflecting and measuring the mathematical literacy of teachers [11].

From the existing literature, we can find that many scholars at home and abroad have studied mathematics teachers' professional quality, including mathematical knowledge, mathematical ability and mathematical teaching ability. Because here is to explore mathematical quality of free normal students, combined with the characteristics of this group of normal students (compared with the teachers, they are lack of practical teaching experience, especially in lower grade undergraduate normal students is even more so), and researchers believe that in the discussion about the professional quality of free education, can use mathematical knowledge, mathematical ability and mathematical affection 3 dimensions to describe. There have been many literatures at home and abroad for the study of mathematical knowledge and mathematical ability. Professional knowledge, professional ability and professional affection (literature with "professional attitude" and "professional beliefs" and other words) for a good teacher is indispensable. Similarly, a mathematics education professional free normal students to become good mathematics teachers, only with mathematical knowledge and mathematical ability is not enough, but also must have the professional affection of Mathematics (here called "Mathematical 
affection"). Mathematical affection refers to the individual free normal students in the future mathematics education emotional attitudes, values and beliefs of the fusion, is the fundamental purpose of research on mathematics free normal sustainable development of professional quality, is to discuss the present situation of mathematical free normal students' professional quality in 3 dimensions of mathematical knowledge, mathematical ability and mathematical affection, further analysis of the relationship between mathematical knowledge, mathematical ability and mathematical affection, and the difference between mathematical quality in gender and grade, revealing the laws of mathematics free normal students professional quality formation and development, improving the mathematical description of possible ways of free normal students mathematical professional quality.

\section{Research Methods}

Survey Objects. Select 50 students of Tonghua Normal University, mathematics and applied mathematics professional free normal college, including 20 male students and 30 female students; including 25 freshmen, 25 sophomores.

Survey Methods. On the basis of reference related literature and research related theory knowledge, the questionnaire of mathematical professional quality of free normal college students was compiled. The questionnaire is composed of 4 parts. The first part is the basic information of mathematics free normal college students, including gender and grade; the second part is the mathematical knowledge of 5 scale, from first to tenth; the third part is mathematical ability, from eleventh to twentieth; the fourth part is the mathematical affection of 5 scale from twenty-first to thirtieth. The second to fourth part is the main part of this questionnaire, including mathematical professional quality of mathematics free normal students in 3 dimensions: mathematical knowledge, mathematical ability and mathematical affection, a total of 30 questions. The questionnaire was revised, the reliability and validity of the questionnaire were all up to the requirements.

The questionnaire using 5 point scoring method, do not have a record of 1 points, basic does not have a record of 2 points, the general has a record of 3 points, compared with a record of 4 points, complete with a record of 5 points. If the score higher, the impact of the factors on the professional quality of free normal college students are greater.

Investigation Process. Taking the grade as a unit, in advance that the survey object has the time and place of the first grade, the questionnaire is issued before the student's meeting with the help of the grade instructor. First of all, the main test before completing the questionnaire, so that the purpose of the questionnaire to be known, the general structure of the questionnaire and the need to pay attention to the process of the questionnaire. Test time is about 10 minutes. When the students completed the questionnaire immediately after the recovery, to recover the initial finishing, to recover 50 valid questionnaires. According to the results of the questionnaire, the results of the questionnaire were entered into SPSS20.0 for statistical analysis of the data. The questionnaire volume recovery details as shown in table 1.

Table 1 Distribution of the questionnaire

\begin{tabular}{|c|c|c|c|}
\hline grade & male student & female student & total number \\
\hline sophomore & 9 & 16 & 25 \\
\hline freshman & 11 & 14 & 25 \\
\hline total number & 20 & 30 & 50 \\
\hline
\end{tabular}

\section{Research Results and Analysis}

Descriptive Statistics. The basic situation was analyzed by descriptive statistics, as shown in table 2 .

Table 2 Descriptive statistics of questionnaire

\begin{tabular}{|c|c|c|c|}
\hline project & average number & standard deviation & average \\
\hline mathematical knowledge & 33.72 & 4.67 & 3.13 \\
\hline mathematical ability & 34.50 & 5.51 & 3.29 \\
\hline mathematical knowledge & 38.44 & 5.94 & 3.86 \\
\hline
\end{tabular}


Table 2 shows that the mathematical affection obtained the highest score, followed by the mathematical knowledge of the score, the mathematical ability of the lowest score. This shows that the mathematical affection of free normal students is higher than the level of mathematical knowledge and ability.

The cause of this result is the following aspects in mathematical ability with low level: the development of mathematics teaching plan and the ability to write teaching ability; teaching methods and strategies; the specific content of the ability to teach mathematics; mathematics teaching ability strain; ability of mathematical thinking can be expressed by verbal and written, visual etc. mathematics teaching summary and reflection ability; mathematics teaching using computer and calculator; the use of teaching software and media making mathematics courseware ability etc.. On the other hand, the following aspects have a higher degree of affection in Mathematics: Tendency of confidence to teach mathematics; willing to become a math teacher's desire for students will pay; and cultivate students' interest in learning mathematics confidence; love mathematics and constantly learning new knowledge, mathematics inquiry mathematics problem desire; constantly improve their mathematics the desire of teaching skills.

Gender Differences. On mathematical professional quality of the gender comparison, statistical results as shown in table 3 .

Table 3 Gender differences in the quality of Mathematics

\begin{tabular}{|c|c|c|c|c|}
\hline project & gender & number & average & standard deviation \\
\hline mathematical & male & 20 & 34.43 & 5.20 \\
\cline { 2 - 5 } knowledge & female & 30 & 33.15 & 4.09 \\
\hline mathematical & male & 20 & 33.68 & 5.71 \\
\cline { 2 - 5 } ability & female & 30 & 32.11 & 5.52 \\
\hline mathematical & male & 20 & 37.29 & 5.61 \\
\cline { 2 - 5 } affection & female & 30 & 38.02 & 5.18 \\
\hline mathematical & male & 20 & 105.40 & 13.99 \\
\cline { 2 - 5 } professional quality & female & 30 & 103.28 & 12.03 \\
\hline
\end{tabular}

From table 3, we can see that in the random sample of 50 students in the free normal school, male students and female students of the mathematical professional quality of the gender difference is not obvious. However, the average quality of male students is divided into 105.40, and the average quality of female students is divided into 103.28. Therefore, the male students overall average score of the professional quality of mathematics is slightly higher than that of female students. In mathematical knowledge and mathematical ability, the male students' scores are higher than female students, but in the mathematical affection of female students score higher than male students.

The results of this study show that: in the number and operations, algebra, geometry, measurement, probability, statistics, discrete mathematics, computing ability, demonstration ability, reasoning ability, problem-solving ability, modeling ability, communication ability and appreciation ability, the use of tools and technology ability etc., the male students are higher than female students. In the aspects of interest, mathematics belief, mathematical consciousness and tendency, mathematical temperament, and so on, female students are higher than male students.

Grade Difference. Mathematical professional quality of free normal students carry on the comparison, statistical results as shown in table 4.

Table 4 Grade difference of mathematical professional quality

\begin{tabular}{|c|c|c|c|c|c|}
\hline $\begin{array}{c}\text { (I) } \\
\text { grade }\end{array}$ & $\begin{array}{c}\text { (J) } \\
\text { grade }\end{array}$ & $\begin{array}{c}\text { average } \\
\text { difference (I-J) }\end{array}$ & $\begin{array}{c}\text { standard } \\
\text { deviation }\end{array}$ & $\begin{array}{c}\text { Significant } \\
\text { test }\end{array}$ \\
\hline freshman & sophomore & 3.28 & 2.11 & 0.122 & $>0.05$ \\
\hline
\end{tabular}


The variance homogeneity test of the data was carried out before the analysis of variance, and the homogeneity of variance was found from the test result, which indicated that the data was suitable for the analysis method.

From the data results can be found, in the mathematical professional quality of free normal students, from this, we can know that there is no significant difference.

Correlation Analysis. Mathematical professional quality of free normal students to carry on the comparison, statistical results as shown in table 5.

Table 5 Correlation analysis of influencing factors of mathematical professional quality

\begin{tabular}{|c|c|c|c|c|c|}
\hline & & $\begin{array}{l}\text { mathematical } \\
\text { knowledge }\end{array}$ & $\begin{array}{l}\text { mathematical } \\
\text { ability }\end{array}$ & $\begin{array}{l}\text { mathematical } \\
\text { affection }\end{array}$ & $\begin{array}{l}\text { mathematical } \\
\text { professional } \\
\text { quality }\end{array}$ \\
\hline \multirow{2}{*}{$\begin{array}{l}\text { mathematical } \\
\text { knowledge }\end{array}$} & pearson correlation & 1 & $0.633 * *$ & $0.431 * *$ & $0.819 * *$ \\
\hline & significant (bilateral) & & 0.000 & 0.000 & 0.000 \\
\hline \multirow{2}{*}{$\begin{array}{c}\text { mathematical } \\
\text { ability }\end{array}$} & pearson correlation & & 1 & $0.480 * *$ & $0.875 * *$ \\
\hline & significant (bilateral) & & & 0.000 & 0.000 \\
\hline \multirow{2}{*}{$\begin{array}{l}\text { mathematical } \\
\text { affection }\end{array}$} & pearson correlation & & & 1 & $0.767 * *$ \\
\hline & significant (bilateral) & & & & 0.000 \\
\hline \multirow{2}{*}{$\begin{array}{l}\text { mathematical } \\
\text { professional } \\
\text { quality }\end{array}$} & pearson correlation & & & & 1 \\
\hline & significant (bilateral) & & & & \\
\hline
\end{tabular}

Note: $* *$ indicates a significant correlation between the 0.01 (bilateral) levels.

The results shows that: (1) mathematical professional quality and mathematical knowledge, mathematical ability and mathematical affection have significant positive correlation, and have significant $\mathrm{P}=0.000<0.01$, the correlation coefficients were $0.819,0.875$ and 0.767 , indicating the correlation mathematical ability and mathematics in the professional quality of the largest, followed by mathematical knowledge and mathematical affection; (2) there is a significant positive correlation of mathematical knowledge and mathematical ability of mathematics free normal students. Among them, mathematical knowledge and mathematical ability was $\mathrm{P}=0.000<0.01$, the correlation coefficient is 0.633 , therefore, the mathematical knowledge of students' mathematical ability is strong; (3) there is significant positive correlation, mathematical knowledge and mathematical affection of mathematics free normal students, the mathematical knowledge and mathematical affection was $\mathrm{P}=0.000<0.01$, the correlation coefficient was 0.431 , therefore, mathematical affection of the students mathematical knowledge good is positive; (4) there is a significant positive correlation, mathematical ability and mathematical affection, mathematical ability and mathematical affection was $\mathrm{P}=0.000<0.01$, the correlation coefficient is 0.480 , therefore, the mathematical ability of students mathematical affection also actively. In general, mathematical knowledge and mathematical ability of the largest correlation, followed by the relationship between mathematical ability and mathematical affection, mathematical knowledge and mathematical affection of the smallest.

Regression Analysis. The dependent variable to mathematical quality in mathematics free normal syudents as with mathematical knowledge, mathematical ability and affection variables, using regression analysis (forced entry), multiple regression analysis, the analysis results are shown in table 6.

Table 6 Multivariate regression analysis

\begin{tabular}{|c|c|c|c|}
\hline project & standardized regression coefficient & $T$ & significant \\
\hline mathematical knowledge & 0.359 & 5.21 & 0.000 \\
\hline mathematical ability & 0.427 & 6.03 & 0.000 \\
\hline mathematical affection & 0.419 & 6.01 & 0.000 \\
\hline
\end{tabular}

It is found that the effects of mathematical knowledge, mathematical ability and mathematical affection on mathematical quality are not independent, and there are complex and interwoven 
relationships between them. In order to understand the influence of mathematical knowledge, mathematical ability and mathematical affection on mathematical professional quality, the method of path analysis is used to analyze the relationship between them, as shown in Fig. 1 .

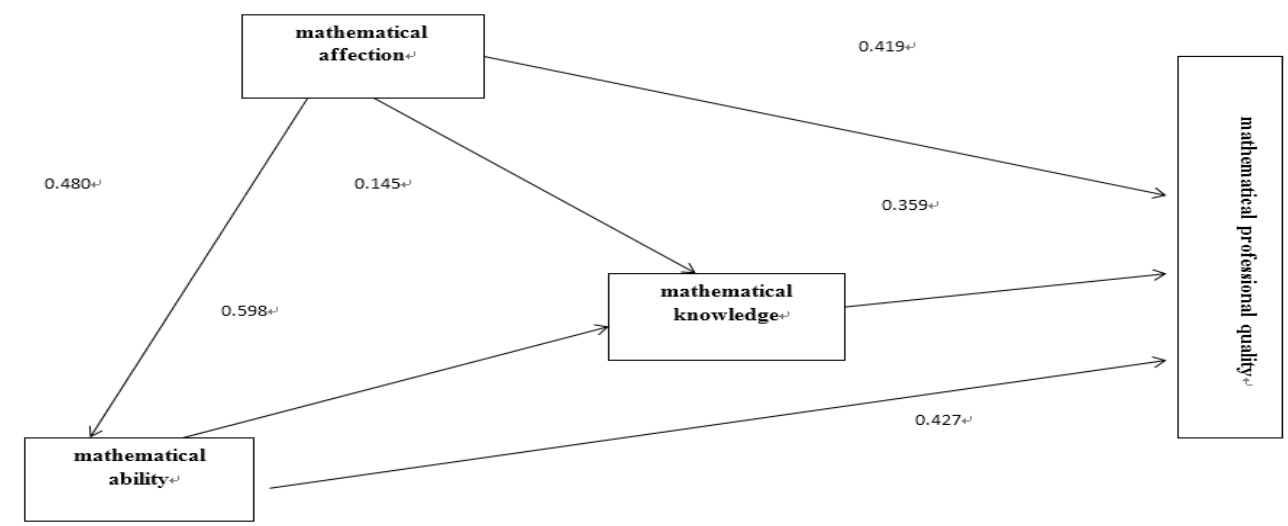

Figure 1 Three impact path for mathematical professional quality of free normal college students

Fig. 1 shows the path of mathematics affecting tuition free normal students professional quality is 7 issue, the direct impacts are: mathematical knowledge, mathematical ability, mathematical professional quality. The indirect paths are: mathematics mathematical ability, mathematical affection, affection and professional quality; mathematics mathematical knowledge, mathematical ability, the number of mathematical professional quality; learning knowledge, mathematical professional quality; mathematical affection, mathematical ability, mathematical knowledge, mathematical professional quality.

\section{Recommendations}

(1) To strengthen the training of mathematical ability of free normal college students. From the analysis of the survey data can be seen, in the mathematical knowledge, mathematical ability and affection factors in 3 dimensions, in addition to individual projects and mathematical affects relatively high scores, the score of two dimensions and single item scores are low, but after two and two more Mathematical affection. This shows that the mathematical free normal students have good mathematical affection, but the relative lack of mathematical knowledge and ability, need to improve, in particular, to strengthen the training of mathematics teaching ability. Can carry out a number of extracurricular activities, can improve math skills, for example, lecture contest, class game, courseware competition, reading, games, competitions, three Mandarin words, math contest, game board games, writing competitions and other modeling. The continuous development for the reform of education, on the teacher's job is about to put forward a new and higher requirements, the normal students will face more and more severe challenges. Therefore, as free normal school students, to constantly update their corresponding theoretical knowledge, continuous learning, and constantly improve their mathematical ability.

(2) Attach importance to the formation of mathematical concept knowledge and mathematical structure knowledge. The analysis results of the survey data show that, on the content of mathematical knowledge, have the degree of free normal students' mathematical knowledge to the traditional high, while the idea of mathematical knowledge structure is not too high. It has been studied that the knowledge of mathematical concepts and the knowledge about the whole structure of mathematics can be regarded as the real high quality normal students or teachers. Do not have the idea of mathematical knowledge the students or teachers, will be very difficult to understand mathematics essence, content fundamentally cannot really feel the value of mathematical knowledge, mathematics occurrence and development process, and the application of mathematical thinking in various practical situations; at the same time, isolation of mathematical knowledge, it is not comprehensive to use mathematical knowledge, 
can not understand and comprehend the idea and method of knowledge, can not understand the essence of mathematics.

(3) The gender differences in the training of the professional quality of free normal college students can not be ignored. According to the analysis of the survey data, it is found that male students are higher than female students in the overall average of mathematical professional quality. In mathematical knowledge and mathematical ability, male students' scores are higher than female students, but the female students' scores in mathematical affection is higher than that of male students. This shows that there is a certain degree of gender differences in the professional quality, therefore, in the process of teacher education to pay attention to this problem. In the comprehensive improvement of the professional quality of mathematics, male students should pay more attention to the cultivation of mathematical affection, and female students should pay more attention to the cultivation of mathematical knowledge and mathematical ability.

(4) The training strategy development of mathematical knowledge to the ability of mathematics and mathematical affection transformation. Research found that some free normal students have a high degree of mathematical knowledge, but the degree of mathematical ability and mathematical affection is not high. This shows that although the free normal students have a higher quality of mathematical knowledge, but lack of education practice, theoretical knowledge and practical experience. Besides, abundant mathematical knowledge can not be well applied to the teaching practice, this will make the free normal students lose confidence in practice, which has the degree mathematical affection quality to reduce, and ultimately affect the development of free normal students mathematical professional quality. Therefore, teachers should focus on the development of mathematical knowledge to mathematical ability and mathematical transformation of the cultivation strategies to help free normal college students to improve mathematical quality.

\section{Acknowledgements}

This work was financially supported by" Research on the training mode of free normal students in mathematics and applied mathematics major" (JG2016215), which was approved by Tonghua Normal University as "the talent training mode reform project".

\section{References}

[1] W.M.Yang and Zh.J.liang: The new curriculum standard of high school mathematics has put forward a high demand for mathematics teachers' mathematics accomplishment. Journal of Mathematics Education, Vol.14 (2005) No.3, p. 87-88.

[2] Z. S.Mei, B.Jia and W. Rui: Quantitative analysis of the influential factors of learning motivation of free normal school students. Journal of Mathematics Education, Vol.18 (2009) No.6, p. 49-53.

[3] Z. B. Man and L.Y.Er: The function of teaching evaluation and case study of developing normal students of mathematics. Journal of Mathematics Education, Vol.17 (2008) No.1, p. 95-98.

[4] Z.X. Gui: Reflections on the belief change of normal college students of mathematics. Journal of Mathematics Education, Vol.19 (2010) No.2, p. 15-18.

[5] L.Miao, M.Q. Xiong and W. Z.Ping: Investigation on the students' classroom teaching skills of professional teachers in Higher Normal Colleges. Journal of Mathematics Education, Vol.18 (2009) No.1, p. 37-40.

[6] G.Xi, D. Huaig and X. B.Yan: Mathematical literacy analysis. Journal of Mathematics Education, Vol. 17 (2008) No.5, p.22-24.

[7] C.G.Wen: mathematical quality. Journal of Mathematics Education, Vol.6 (1997) No.3, p.16-17.

[8] Q.P.Ling: Thinking about mathematical quality of mathematics education major in Higher Normal College. Journal of Mathematics Education, Vol.6 (1997) No.3, p.11-14. 
[9] W.Wang: Survey on mathematics teacher's quality in middle school. Journal of Mathematics Education, Vol.8 (1999) No.3, p. 45-47.

[10]D. F.Zhao: In order to achieve the training of mathematics teachers of high quality. Journal of Mathematics Education, Vol.9 (2000) No.1, p. 69-71.

[11] H.D. Shun: Mathematics curriculum quality research review. Teaching Materials, Vol. 30(2010) No.12, p. 50-54. 